\title{
The Pragmatism of Improving Vocabulary Acquaintance to Develop Writing Skills of Engineering Undergraduates
}

\author{
Sree Devi Jasti \\ Dept. of Humanities \& Science,Vidya Jyothi Institute of Technology, Hyderabad \\ Research Scholar, KL University, AP, India, Email: sreejasti99@gmail.com
}

\begin{abstract}
The current research article was basically carried out to reveal the effectiveness of vocabulary awareness in developing the writing skills of undergraduate engineering students. The investigation was conducted at Vidya Jyothi Institute of Technology, Hyderabad. The investigation began with selecting 120 students of Computer Science Engineering who arelearning English Language communication skillsin their third year first semester (2018-19) in Advanced Communication Skills Lab. The teacher to conduct the research had split the students equally into two groups. The two groups were regarded as one experimental group. The quantitative and experimental methods were used deciding on the pre and post-test as the main instrument to obtain the data which was tried out on the experimental group. The SPSS (Statistical Package for Social Sciences) program was used in the analysis of the data which have come out with satisfying results that vocabulary awareness is an effective method and strategy that can be adopted by teachers in their pursuit of developing the writing skills of their students particularly engineering undergraduate students.
\end{abstract}

Key Words: Vocabulary awareness, writing ability, language devices

Introduction: Students undergo several difficulties in their learning process, particularly in writing which is one of the most difficult skills. This is because writing comprises all the aspects and devices of the Language such as Syntax, Semantics, Lexical items and Punctuation.

It has been remarkedthat the ability to write effectively hinges upon having an adequate vocabulary even more than does the ability to read. Once students have learned to decode words, they may be able to read and use many words that are unfamiliar to them. They may even be able to determine accurate meanings of unfamiliar words simply by examining the context in which those words are used. During the writing process, however, a student does not have the luxury of examining the context in which a word is used; he or she is creating the context. Therefore, the writer must be able to spontaneously recall words that are known not only by sight, but that is understood to use correctly.

Revealing the effectiveness of vocabulary awareness in developing writing skillsamong undergraduate engineering students, is the main objective of the current research, as well as to fulfill the following objectives:

1. To increase the students' vocabulary awareness to develop their writing skills.

2. To enable students to produce accurate written work.

Statement of the Problem Vocabulary has a great impact on learners' writing ability. That is, most of the English Language learners face difficulties in choosing the correct lexical items in any writing task which affects their written performance. Thus, this research paper shall investigate and look for further strategies and suggestions for teaching and learning vocabulary methods to increase students' vocabulary awareness that help them overcome these difficulties they face in writing.

Research Questions and Hypotheses The main objective of the current research is to recognize the effectiveness of vocabulary awareness in developing engineering undergraduates' writing skills. As such, to fulfill this aim the following questions need to be answered:

1. To what extent can vocabulary awareness increase students' motivation to develop their writing skills?

2. In what way does learners' vocabulary awareness contribute in producing accurate written work?

In seeking answers to the above questions, the hypotheses that have been formulated areas follows:

H1: Vocabulary awareness increases students' motivation to develop their writing skills.

H2: Learners' vocabulary awareness contributes to producing accurate written work.

The Importance of Writing According to Hedge (1988), most writing in English classroom is undertaken as an aid to learning, for example, to consolidate the learning of new 
structures represented in general or technical vocabulary, also to help students remember new bits and pieces of language. In this context the role of writing is different from its role with each technical subject and the vocabulary it uses; it allows students to see how they are progressing and to get feedback from the teacher, while allowing teachers to monitor and diagnose problems. Much of this writing is at the sentence level, but successful writing depends on more than the ability to produce clear and correct sentences. So the teacher is interested in tasks which help students to write whole pieces of communication, to link and develop information, ideas, or arguments for a particular reader or group of readers.

Therefore, writing tasks which have whole texts as their outcome relate appropriately to the ultimate goal of those learners who need to write English in their social, educational, or professional lives. Some of our students already know what they need to or able to write in English. Few others may be uncertain about the nature of their future needs. So the role of the teacher is to build the communicative potential among the students.

Students have to prove their competence in English by producing Imaginative Conversations in English, Letter Writing, Report writing, Portfolio writing or Resume for examinations in the ACS lab. It is noticed that, there have been substantial numbers of students who have no identifiable needs, for written English, beyond the need to attempt their exam, but who still enjoy writing, who are motivated to use their language resources in producing descriptions, reviews, and essays, simply to practice and improve their English.

The Skill of Writing It has been stressed by Frith, J, (2009), that learning English requires an integration of the four skills listening, speaking, reading and writing. The latter is a necessary skill that has to be developed since it is a manifestation of the learner's performance in a foreign language. Therefore, the teacher has been looking for effective methods and approaches to teach writing so that Learners' written production could be improved.This paperis going to introduce the skill of writing and to concentrate on the most common approaches to teach it. The purpose is to gain knowledge about the best way of writing that could be taught. Overcoming this problem may help them to write appropriately if it is realized by teaching collocations explicitly. Directions to do so are explained and followed by the materials that facilitate the process of building learners' awareness of the most common collocations.

Finally, the roles of both teachers and learners have been discussed. Writing is a difficult skill a learner has to master, both native and non-native speakers may lack the competence necessary to make them good writers because learners could not express their ideas effectively without this competence. Within this scope, Tribble (as cited in Frith, J, 2009) argues that; it is through the mastery of writing that the individual comes to be fully effective in an intellectual organization, not only in the management of everyday affairs but also in the expression of ideas and arguments". Thus, students of professional courses like engineering, seeking to learn language for their professional endeavors are struggling to write correctly since they face many obstacles toward a correct English composition. Writing necessitates, at least, a basic knowledge of grammar, lexis, and vocabulary, and the ability to express ideas in an appropriate English language unaffected by the mother tongue influence.

What the learners ought to reach in writing is proficiency, which is used by some writers to replace "competency". It is agreed by Nunan (1988) on the fact that proficiency is "the ability to perform realworld tasks with a pre-specified degree of skill". Lewis (2000) further considers proficiency as a term that refers to three characteristics: accuracy, fluency, and complexity. Firstly, the researcher has to consider accuracy versus fluency; under the communicative approach, accuracy is not the main interest as far as it does not hinder the communication of meaning. What is aimed at is not the form but rather the meaning? The communicative approach does favor fluency, whereas the audio-lingual and grammar translation approaches favor accuracy. Hence, considering the 'accuracy/fluency' question from the viewpoint of teaching approaches and methodologies area little problematic. Thus, the teacher has to encourage the learner's fluency first, and then accuracy would follow at the end of the writing process. Secondly, "complexity" is, according to Lewis (2000), the improvement of students' writing especially at advanced levels in their core subjects as well. It indicates "the writer's ability to construct noun phrases which are high in informational content", andfurther the noun phrases are neglected in contrast to verb phrases that are the focus of traditional grammar. As a result, the accuracy/fluency dichotomy has to be replaced with an endeavor to direct the students towards the complexity of the language. This may lead to both fluency 
and accuracy. Hence, expertise in English language writing for professional purpose will increase to a degree that it could challenge the proficiency especially if students are taught the vocabulary that improve their writing style and make it more natural.

Vocabulary Definition It has been broadly defined by Kamil and Hiebert, (2007) thatvocabulary is the knowledge of words and word meanings; however, vocabulary is more complex than this definition suggests. First, words come in two forms: oral and print. Oral vocabulary includes those words that we recognize and use in listening and speaking. Print vocabulary includes those words that we recognize and use in reading and writing. Second, word knowledge also comes in two forms, receptive and productive. Receptive vocabulary includes words that we recognize when we hear or read them. Productive vocabulary includes words that we use when we speak or write. Receptive vocabulary is typically larger than productive vocabulary and may include many words to which we assign some meaning, even if we do not know their full definitions and connotations - or ever use them ourselves as we speak or write.

According to Farrell (2009) research has indicated that people store words semantically, not alphabetically like in a dictionary; that the more we use a word, the easier it is to remember; and that we will remember faster the word we have more recently used. Many times it is suggested that students read as much as they can so they can expand their vocabularies. Here the English teachers have an important role to play in motivating the students to enlarge their vocabulary banks by intervening directly and teaching them how to do this. Many teachers try to accomplish this by getting their students to memorize word lists or look at synonyms and antonyms of a word and then doing fill-inthe-blank exercises connected to these memorized words. These efforts may be useful, but recent research has indicated that English Language Learners acquire vocabulary more effectively when they are directly involved in constructing the meaning of a word rather than memorize definitions of synonyms.

The Importance of vocabulary awareness is very important to language learners. So, Words are the building blocks of a language since they label objects, actions, ideas without which people can't convey the intended meaning. A prominent role of vocabulary knowledge in second or foreign language learning has been recently recognized by theorists and researchers. Accordingly, numerous types of approaches, techniques, exercises, and practices have been introduced into the field to teach vocabulary. Thus the present researchhas considered that teaching vocabulary should not only consist of the teaching of specific words but also aim at equipping learners with strategies necessary to expand their vocabulary knowledge, as words serve different purposes when reading, writing and speaking. A reader needs to recognize words and assign meaning to them; a writer and speaker must choose words to convey ideas. A person with limited vocabulary will have difficulty in expressing and understanding ideas.

It has been argued that a rich vocabulary is a critical element of reading ability. The research has identified vocabulary knowledge as the most important factor in reading comprehension. They state a strong link between reading and writing. Reading and writing are two analogous and complementary processes in which both involve generating ideas or organizing ideas to logically drafting them a number of times to achieve cohesion, and revising ideas as is appropriate. The processes are so closely aligned that some researchers even advocate teaching reading and writing simultaneously rather than as two separate aspects.

Word knowledge has particular importance in literate societies. It contributes significantly to the achievement in the knowledge gain ofknowledge in core subjects of the course curriculum, as well as in the formal and the informal ability of speaking \&writing by an individual. Most people feel that there is a common sense relationship between vocabulary and comprehension, messages are composed of ideas, and ideas are expressed in words.

Vocabulary knowledge and writing It has been stated by Duin and Graves (1987), that it is well understood that words and language play a critical role in writing. Significant research has been conducted on the effects of vocabulary instruction on reading performance but studies investigating vocabulary instruction and writing are few.

It is reported that the ability to write effectively hinges upon having an adequate vocabulary even more than the ability to read. Once the students have learned to decode words that are unfamiliar to them, they even are able to determine accurate meanings of unfamiliar words simply by examining the context in which those words are used. During the writing process, however, a student does not 
have the luxury of examining the context in which a word is used; he or she is creating the context. Therefore, the writer must be able to spontaneously recall words that are known not only by sight, but that is understood well enough to use correctly.

Effect of vocabulary instruction on writing It has been argued by Graves (1987) and Johnson (1999) that efforts to improve writing performance through instruction have been limited making a generalization about the role of vocabulary instruction unwarranted. However, a few studies have been conducted to investigate the effect of vocabulary instruction on writing.

It has been provided by Duin and Graves (1987) some possible explanation for the effectiveness of groups receiving rich instruction: words selected were chosen for and taught around a common topic, students were encouraged to notice and use of words outside of class, vocabulary instruction provided both contextual and definitional information about the word's meaning and students had multiple exposures to words that require deep and active processing.

Using vocabulary to improve writing skills The research progressed on the concept of improvement in vocabulary which will result in improved writing skills only if the teacher is able to create a classroom that takes writing seriously. In such a classroom, process and environment are closely intertwined and interdependent.The process does not come alive unless the environment is conducive to it. The following are techniques used by the teacher to create a writing-centered classroom.

Sharing vocabulary-Students read articles, or listened to ted talks that contain interesting vocabulary; the teacher identified both introduction of new words\& expressions and provide a forum for discussing them.

Offering a variety of writing opportunities:- A writercentered classroom emphasized on using a written expression to communicate ideas. Writing is an important part of all areas of the curriculum (Corona, Spangenberger, $\&$ Venet, 1998). The authors go on to note that students have a greater investment in their writing when they are given choices about their assignments. Such choices may include writing assignments on latest concepts or summarizing from journal articles, news paper articles, outlines of relevant research topics, or any number of variations on the above providing ample time for students to fully experience the writing process. The teaching of writing has been approached as a process that must be studied in depth, and substantial blocks of time should be devoted to writing.

Vocabulary's influence on successful writing I has been pointed out that the process of writing is exceptionally linked to the reading process, and the reading process is heavily dependent upon vocabulary. It naturally follows that writing process is likewise dependent.

Vocabulary development Vocabulary development is critical for English language learners for professional use, especially professional students of engineering, because we know that there is a strong relationship between vocabulary knowledge in English and academic achievement. To be most effective, vocabulary development should be closely related to the subject matter students are studying. So the teacher, teaching vocabulary, hasembed the new words within the context of the text, providing students with a rich contextual environment in which to learn new terms and expand their English vocabulary. A research conducted on vocabulary instruction has determined four main principles that should guide the instruction:

- Students should be active in developing their understanding of words and ways to learn them. Such waysinclude the use of semantic mapping, word sorts, use of concept definition map, and developing strategies for independent word learning.

- Students should personalize word learning through such practices as vocabulary self- collocation strategy,mnemonic strategies, and personal dictionaries.

- Students should be immersed in words by providing language environments that focus on words and drawstudents' attention to the learning of words. Words walls, personal word study notebooks and dictionaries, and comparing/ contrasting words with the same morphemic element aid students in recognizing and using words around them.

- Students should build on multiple sources of information to learn words through repeated exposures. Letting students see and hear new words more than once and drawing on multiple 
sources of meaning is important for vocabulary development.

Method and design of the study To achieve the aim of the research, the experimental and the quantitative methods have been used. To collect the data of the research, one instrument was assigned namely the test as a data gathering tool. The research design was well designed to yield the effectiveness of vocabulary awareness in developing the engineering undergraduates' writing skills.

Subjects The subjects of this research are students of English language Advanced Communication Skills Lab, of Vidya Jyothi Institute of Technology, distributed among two groups. The participants of the first group and were the students of section A of the Computer Science Engineering third year first semester students, and the participants of the second group were the students of section B of the Computer Science Engineering third year students of the first semester, in Vidya Jyothi Institute of Technology of the academic year (2017-2018). Their overall number is 120 students, 60 students from the section $\mathrm{A}$, and 60 students from section B selected purposively and they study English Language Communication for professional needs in the Advanced Communication Skills Lab.

Instrumentation In this paper, the test was used as a data collection tool. It consisted of five questions. Each question was designed carefully to assess the students' awareness of vocabulary. The first question is filling gap question, in which the students were given 20 words to fill in the blanks in a passage. The second question is a multiple choice question used to measure the students' vocabulary size. In this question, each word appears in the context of a sentence; the students choose the correct definition from four choices. They have a fairly developed idea of the meaning of the word because the correct answer and the distracters usually have elements of meaning. The third question is matching. As for the fourth question includes prefixes and suffixes. The fifth question contains two parts, synonyms, and antonyms. The pre-test was tried out on both groups of CSEA\&CSE B students before teaching vocabulary. Then, the post-test was carried out to the same group of students after the teaching of vocabulary.

Procedure The test was used as a tool for data collection, where particular procedures and steps were followed to collect data. It took about 60 minutes for all subjects to finish. During the experiment, students in two groups were taught as one experimental group. In the two hours weekly class, experimental group was given a series of lectures on vocabulary. During treatment lecture, activities were elaborated to raise students' awareness of vocabulary. Treatment lectures were selected from English books and exercises downloaded from the internet. The students were encouraged to explain different uses of words, providing them topic-related sessions to vocabulary use.

Data analysis Certain statistical strategies were used here in the analysis of data. These tools were frequency, percentage, one sample t-test, paired sample t-test, independent sample t-test using SPSS, Statistical Package for Social Sciences in the analysis of the data obtained by the designed tool. The results of the both tests have been collected and counted in order to check their results that assisted the researcher to make sure of the effectiveness of vocabulary awareness and in developing undergraduates' writing skills.

\section{Testing the Hypotheses via Test Results}

H1: "Vocabulary awareness increases students' motivation to develop their writing skills".

\section{One sample t-test for the first hypothesis}

\begin{tabular}{|l|l|l|l|l|l|}
\hline $\begin{array}{c}\text { Expected } \\
\text { mean }\end{array}$ & Mean & St.d. & t-value & d.f & p-value \\
\hline 12 & 7.08 & 1.90 & -18.27 & 49 & 0.000 \\
\hline
\end{tabular}

The above table (1) showed that the p-value equals (0.000), is less than the significance level $(0.05)$ which means that there is a significant statistical difference between the expected mean (12) and the actual mean (7.08). When the actual mean is less than the expected mean, these differences confirmed the first hypothesis which is "vocabulary awareness increases students' motivation to develop their writing skill".

Paired Sample T-test for Students Skill Test class

\begin{tabular}{|c|c|c|l|l|l|c|}
\hline Skill & $\begin{array}{l}\text { Test } \\
\text { Class }\end{array}$ & Mean & St.d & t-value & d.f & p-value \\
\hline $2^{\text {nd }}$ Class \\
\hline \multirow{2}{*}{ Q1 } & Pre & 1.88 & 1.604 & -10.422 & 39 & 0.000 \\
\cline { 2 - 5 } & Post & 3.53 & 1.935 & & & \\
\hline \multirow{2}{*}{ Q2 } & Pre & 6.15 & 2.143 & -10.422 & 39 & 0.000 \\
\cline { 2 - 5 } & Post & 8.63 & 2.361 & & & \\
\hline \multirow{2}{*}{ Q3 } & Pre & 12.98 & 1.687 & -6.811 & 39 & 0.000 \\
\cline { 2 - 5 } & Post & 14.83 & .675 & & & \\
\hline \multirow{2}{*}{ Q4 } & Pre & 4.13 & 1.202 & -8.241 & 39 & 0.000 \\
\cline { 2 - 5 } & Post & 5.60 & 1.277 & & & \\
\hline \multirow{2}{*}{ Q5 } & Pre & 3.15 & 1.748 & -9.297 & 39 & 0.000 \\
\cline { 2 - 4 } & Post & 4.68 & 1.591 & & & \\
\hline
\end{tabular}




\begin{tabular}{|c|c|c|c|c|c|c|}
\hline \multirow[t]{2}{*}{ TOTAL } & & 28.35 & 6.100 & \multirow[t]{2}{*}{-17.541} & \multirow[t]{2}{*}{39} & \multirow[t]{2}{*}{0.000} \\
\hline & & 37.25 & 5.271 & & & \\
\hline \multicolumn{7}{|c|}{$3^{\text {rd }}$ Class } \\
\hline \multirow[t]{2}{*}{ Q1 } & Pre & 2.53 & 1.853 & -7.722 & 39 & 0.000 \\
\hline & Post & 4.70 & 2.574 & & & \\
\hline \multirow[t]{2}{*}{ Q2 } & Pre & 8.35 & 2.045 & \multirow[t]{2}{*}{-7.911} & \multirow[t]{2}{*}{39} & \multirow[t]{2}{*}{0.000} \\
\hline & Post & 9.88 & 2.151 & & & \\
\hline \multirow[t]{2}{*}{ Q3 } & Pre & 13.80 & 1.829 & \multirow[t]{2}{*}{-2.414} & \multirow[t]{2}{*}{39} & \multirow[t]{2}{*}{0.021} \\
\hline & Post & 14.45 & 1.867 & & & \\
\hline \multirow[t]{2}{*}{ Q4 } & Pre & 4.23 & 1.776 & \multirow[t]{2}{*}{-5.596} & \multirow[t]{2}{*}{39} & \multirow[t]{2}{*}{0.000} \\
\hline & Post & 6.00 & 1.754 & & & \\
\hline \multirow[t]{2}{*}{ Q5 } & Pre & 3,65 & 2.155 & \multirow[t]{2}{*}{-6.914} & \multirow[t]{2}{*}{39} & \multirow[t]{2}{*}{0.000} \\
\hline & Post & 4.88 & 1.786 & & & \\
\hline \multirow[t]{2}{*}{ TOTAL } & Pre & 32.18 & 6.968 & \multirow[t]{2}{*}{-13.358} & \multirow[t]{2}{*}{39} & \multirow[t]{2}{*}{0.000} \\
\hline & Post & 40.08 & 6.955 & & & \\
\hline
\end{tabular}

The table (2) above has clearly indicated that the p-values are almost zero or 0.021 in both the pre-and post-tests regarding each skill. The pre means are less than the post means. As a result, it is noticed that there was progress and development in the students' performance in both 2 nd and 3rd levels. Thus, these results strongly confirmed and strengthened the first hypothesis of the article that "vocabulary awareness increases students' motivation to develop their writing skill".

H2: "Learners' vocabulary awareness contributes to producing accurate written work".

One sample T-test for the second hypothesis

\begin{tabular}{|c|c|c|c|c|c|}
\hline $\begin{array}{c}\text { Expected } \\
\text { mean }\end{array}$ & Mean & St.d. & t-value & d.f & p-value \\
\hline 12 & 7.52 & 2.49 & -12.71 & 49 & 0.000 \\
\hline
\end{tabular}

Table (3) showed p-value equals (0.000) is less than significance level (0.05). This means there is significant difference between expected and actual means. The actual mean (7.52) is less than expected mean (12) \& outcome supports2nd hypothesis that "Learners' vocabulary awareness contributes to producing accurate written work".

Paired Sample T-test for Students' Performance

\begin{tabular}{|c|c|c|c|c|c|c|}
\hline Skill & $\begin{array}{c}\text { Test } \\
\text { Class }\end{array}$ & Mean & St.d. & $\begin{array}{c}\text { t- } \\
\text { value }\end{array}$ & d.f & $\begin{array}{c}\text { p- } \\
\text { value }\end{array}$ \\
\hline \multicolumn{7}{|c|}{$2^{\text {nd }}$ Class } \\
\hline \multirow{2}{*}{ Q1 } & Pre & 1.88 & 1.604 & - & 39 & 0.000 \\
\cline { 2 - 5 } & Post & 3.53 & 1.935 & 10.422 & & \\
\hline \multirow{2}{*}{ Q2 } & Pre & 6.15 & 2.143 & - & 39 & 0.000 \\
\cline { 2 - 5 } & Post & 8.63 & 2.361 & 10.422 & & \\
\hline \multirow{2}{*}{ Q4 } & Pre & 4.13 & 1.202 & -8.247 & 39 & 0.000 \\
\cline { 2 - 4 } & Post & 5.60 & 1.277 & & \\
\hline \multicolumn{7}{|c|}{$2^{\text {nd }}$ Class } \\
\hline Q1 & Pre & 2.53 & 1.853 & -7.722 & 39 & 0.000 \\
\hline
\end{tabular}

\begin{tabular}{|c|c|c|c|c|c|c|}
\hline & Post & 4.70 & 2.574 & & & \\
\hline \multirow{2}{*}{ Q2 } & Pre & 8.35 & 2.045 & -7.911 & 39 & 0.000 \\
\cline { 2 - 5 } & Post & 9.88 & 2.151 & & & \\
\hline Q4 & Pre & 4.23 & 1.776 & -5.596 & 39 & 0.000 \\
\cline { 2 - 4 } & Post & 6.00 & 1.754 & & & \\
\hline
\end{tabular}

The table (4) above has clearly shows that the p-values are almost zero or 0.000 in both the pre-and post-tests with regard to each question. The pre means is less than the post means. As a result, it is noticed that there is a progress and development in all students' writing performance due to the vocabulary input they received between the pre and post test duration. Thus, the test results replied to the questions of research and reinforced the second hypothesis that "Learners' vocabulary awareness contributes producing accurate written work".

It is concluded that according to the above-discussed hypotheses and questions, fulfilling the main objectives of the article, vocabulary awareness effectively contributed to the development of writing skills of the students.

Discussion As the statistics revealed that a better performance of students was noticed in the final post-test in which they outperformed their scores in the pre-test. According to this comparison between results in the pretest and the post-test, it was obviously seen that vocabulary awareness had effective influence in developing undergraduate engineering students writing skills. All the subjects in both groups exposed to the same amount of teaching materials of vocabulary knowledge before the experiment and all of learning in English Communication Skills in the ACS Lab as a practical subject. Therefore, they were almost regarded at the same level of language proficiency; however, their abilities were compared in the light of the pre and post test outcomes. They were 120 students split into two groups equally; each one included 60 students but they were all treated as one experimental group. It was summarized that vocabulary awareness is of effectiveness in developing undergraduate engineering students' writing skills besides widening their knowledge of the vocabulary use. In addition to the above-mentioned facts, the hypotheses of the article were proved and there was a clear-cut difference between the students' performance before and after the experiment.

Conclusion The importance of vocabulary as for learners of the CSE A\& B sections of the third year first semester English language Communication skills enhanced the teacher's knowledge for this article and also to look for effective methods and strategies by which the standard of 
learners could be developed in terms of their vocabulary awareness. This article tried to deeply identify the effectiveness of vocabulary awareness in developing undergraduates' writing skills by demarcating the distinction between the scores of the students in the two tests where a significant progress occurred in the learner's writing skills by virtue of the vocabulary teaching materials they have received as a remedy and which has contributed to achieving the main aims of the article. Having discovered the effectiveness of the vocabulary awareness in students' writing skills as shown by the statistical results, it can be assumed that giving students an adequate amount of vocabulary items, help them to achieve the following:

The use of core vocabulary reflects learners' high levels of writing capacities.

\section{References}

1. Brynildssen and Shawna (2000) vocabulary influence on successful writing. ERIC Digest D157.www.eric.ed.gov. ERIC information analysis product (IAPS).

2. Byrne, D. (1999) Teaching writing skills. Longman Handbook for language teachers. Longman: London and New York. British library cataloguing in publication data.

3. Corona, C., Spangenberger, S. and Vent, T (1998). Improving students writing through a Language Rich Environment. M. A. Action Research Project, St. Xavier University and /R//skylight,/6/ pages.

4. Duin, A. and Graves, M. (1987) Intensive Vocabulary instruction as A prewriting techniques. Int. J. Eng. Lang. Lit \&Trans. Studies (ISSN:2349-9451/2395-2628) Vol. 4. Issue.3, 2017 (July-Sept) 474 SADIA OSMAN IBRAHIM et al.,

5. Echevarria, J. Vogt, E., and Short J. (2004) Making content comprehensible for English learners. United States of America: Washington.

6. Farell, C. (2009) Teaching Reading to English language learners. United States of America: Corwin press ASAGE Company.

7. Frith, J. (2009).A Process Genre Approach to Writing Transactional letters. Retrieved August 24, 2009, from http://www.Developingteachers.com/articles. teacher training/processgenre1_james.Htm.

8. Ghazal, L. (2007) Learning vocabulary in E.FL. context through vocabulary learning strategies. Islamic Azad University. (online) Available: www.Novitasroyal, org/Ghazal. Html vol,1 (2) p (84- 91).

9. Hedge, T. (1988) Writing. Oxford: Oxford University Press.
Learner's awareness of vocabulary will have a direct influence on the quality and accuracy oftheir writing

The ability to write effectively depends on having adequate vocabulary items.

Finally, the article recommends that:

Students should be knowledgeable about using and organizing lexical items in incoherent Paragraphs.

Teaching materials should focus on fostering learners to develop their vocabulary.

Adequate practice in using new vocabulary items must be given to the learners to develop good writingskills. And teachers must use effective methods to integrate learners' vocabulary with different writing tasks.

10. Henry, S. and Scott, J. (1999) Linking university and teachers communities: "Athink tank" model of professional development. Teacher education and special education 22(4) 251-267.

11. Johnson, B. (1999) Word works Exploring Language Play. Golden, Co: Fluenum publishing.

12. Kamil, M. and Hiebret, E. (2007) Vocabulary assessment: what we know and what we need to learn. Reading research: vol.42 page (282-296) international reading association. 